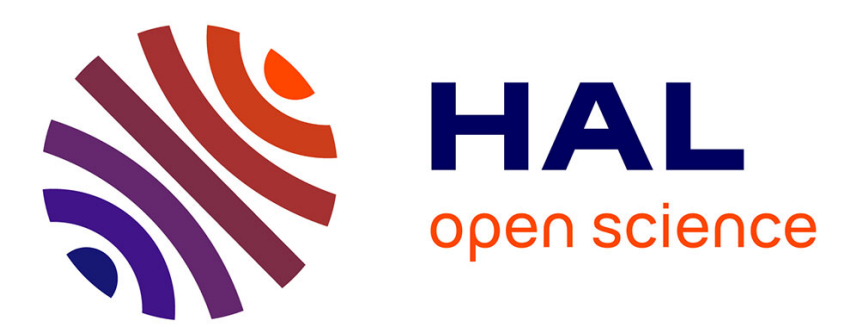

\title{
Bistable FeCoMoB microwires with nanocrystalline microstructure and increased Curie temperature
}

P Klein, R Varga, P Vojtanik, J Kovac, J Ziman, G A Badini-Confalonieri, M Vazquez

\section{- To cite this version:}

P Klein, R Varga, P Vojtanik, J Kovac, J Ziman, et al.. Bistable FeCoMoB microwires with nanocrystalline microstructure and increased Curie temperature. Journal of Physics D: Applied Physics, 2010, 43 (4), pp.45002. 10.1088/0022-3727/43/4/045002 . hal-00569727

\section{HAL Id: hal-00569727 \\ https://hal.science/hal-00569727}

Submitted on 25 Feb 2011

HAL is a multi-disciplinary open access archive for the deposit and dissemination of scientific research documents, whether they are published or not. The documents may come from teaching and research institutions in France or abroad, or from public or private research centers.
L'archive ouverte pluridisciplinaire HAL, est destinée au dépôt et à la diffusion de documents scientifiques de niveau recherche, publiés ou non, émanant des établissements d'enseignement et de recherche français ou étrangers, des laboratoires publics ou privés. 


\section{Bistable FeCoMoB microwires}

with nanocrystalline microstructure and increased Curie temperature

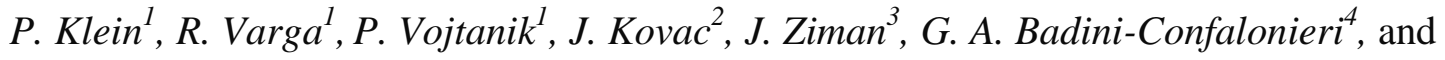
M. Vazquez ${ }^{4}$

${ }^{1}$ Inst. Phys., Fac. Sci., UPJS, Park Angelinum 9, 04154 Kosice, Slovakia

${ }^{2}$ Inst. Exp. Physics, SAS, Watsonova 47, 04001 Kosice, Slovakia

${ }^{3}$ Dept. of Physics, FEI TUKE, Park Komenskeho 2, 04200 Kosice, Slovakia

${ }^{4}$ ICMM CSIC, Campus de Cantoblanco, 28049 Madrid, Spain

Abstract.-

Novel nanocrystalline glass-coated $\mathrm{Fe}_{40} \mathrm{Co}_{38} \mathrm{Mo}_{4} \mathrm{~B}_{18}$ microwires are introduced. They combine advantages of nanocrystalline alloys exhibiting simultaneously increased Curie temperature and magnetic bistability, which is required for modern sensoric and spintronic devices. Positive magnetostriction of the crystalline FeCo grains results in a magnetic bistability, whereas good soft magnetic properties remains stabilized. As a result of mechanical stress induced by the glass-coating, the optimum temperature range for thermal treatment is enhanced up to $600{ }^{\circ} \mathrm{C}$.

Keywords: Magnetic microwires, domain wall, switching field, nanocrystalline materials.

PACS: 75.30.Gw; 75.50.Tt; 75.60.Ej

Corresponding author: Dr. R. Varga,

Inst. Phys., Faculty of Science

University of Pavol Jozef Safarik

Park Angelinum 9, 04154 Kosice

Slovakia

E-mail: rvarga@upjs.sk 


\section{Introduction}

Amorphous magnetic glass-coated microwires are novel materials with outstanding magnetic behavior for micromagnetism studies with high potential for technological applications [1,2,3]. They consist of a magnetic nucleus (which diameter ranges between 1 and $30 \mu \mathrm{m}$ ) coated by a Pyrex-like glass ( 2 to $20 \mu \mathrm{m}$ thick), and they are prepared by quenching and drawing technique. Due to their amorphous structure, the main anisotropies that control their magnetic properties are magnetoelastic and shape anisotropy term. Particularly, in the case of positive magnetostriction microwires, the domain structure consists of single large internal domain with axial magnetization, which is surrounded by the external, radially magnetized, multidomain structure (see Figure 1) [4]. As a result, magnetization process in axial direction runs through the depining and subsequent propagation along entire microwire of a domain wall from the closure domain shown in figure 1 [3]. Such magnetization process results in bistability (e.g. only two magnetization states are allowed: $+M_{s}$ and $-M_{s}$, where $M_{s}$ is the saturation magnetization) [5]. Magnetic bistability is one of the most important futures desired for modern spintronic devices that store and transfer information through the domain wall propagation in thin magnetic wires (such a modern memories [6] and domain wall logic [7]), or in sensoric devices in which two distinct states must be well separated [8]. Advantages of magnetic microwires include their unique magnetic properties, small dimensions and symmetrical shape, cheap preparation and reliability on electrical, mechanical, and corrosive external effects from Pyrex coating. However, due to their amorphous nature, they can suffer aging effect on time and thermal stability.

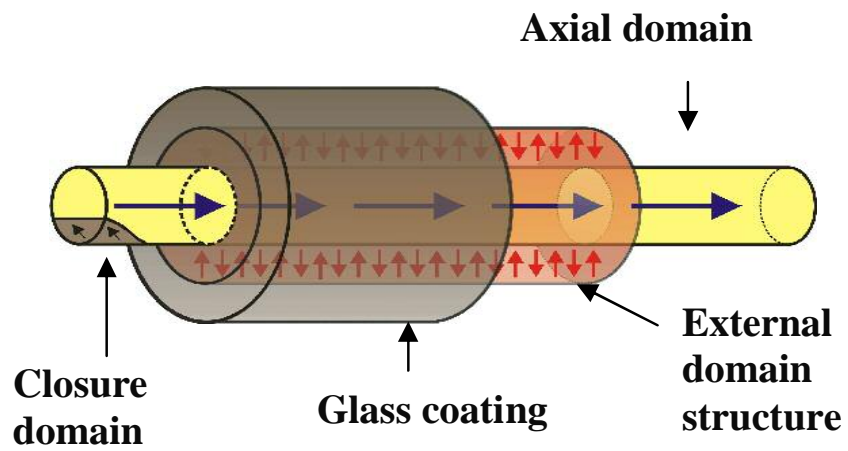


Figure 1.- Schematic domain structure of the amorphous glass-coated microwire with positive magnetostriction.

On the other hand, certain magnetic materials with nanocrystalline structure show excellent soft magnetic properties accompanied by a high structural stability [9]. They are obtained by partial crystallization of the precursor amorphous matrix after suitable thermal treatment, and their structure consists of randomly oriented crystalline grains (approximately $10 \mathrm{~nm}$ in size) embedded in the residual amorphous matrix [10]. The crystalline grains are exchange-coupled through the amorphous matrix that results in an averaged out effective crystalline anisotropy. Moreover, the magnetostriction of crystalline grains can be tailored to become negative, contrary to the positive sign of magnetostriction of amorphous matrix, hence the effective magnetostriction takes a vanishing value, which drastically reduces the magnetoelastic anisotropy.

Scientists try to combine ultrasoft magnetic properties and high structural stability of nanocrystalline materials with the shape anisotropy of magnetic microwires $[4,11,12]$. However, very small anisotropy sometimes counter plays the requirement of high positive magnetostriction so, nanocrystalline microwires lost their bistability [13]. On the other hand, the different thermal expansion coefficient of metallic nucleus and glasscoating can result in huge stresses during the nanocrystallization processes (induced by annealing of the precursor amorphous phase). In addition,instead of desired $\alpha$-(Fe,Si), $\gamma$ Fe phase can crystallize. This phase deteriorates the magnetic properties owing to its nonferromagnetic character [14,15].

Most of the above-described questions can be solved by employing nanocrystalline alloys, like FeNiMoB [16] which crystallize into nano-size $\gamma$-FeNi ferromagnetic phase, characterized by positive magnetostriction. Moreover, the optimum annealing temperature for nanocrystallization, of around $400^{\circ} \mathrm{C}$, in such alloys is reduced in comparison with typical nanocrystalline materials $\left(550^{\circ} \mathrm{C}\right)$, thus the compressive stresses from the glass coating are substantially reduced. Nevertheless, the only disadvantage of nanocrystalline FeNiMoB-based microwires is their relatively small magnetization and low Curie temperature, and the very narrow range of annealing temperatures to reach optimum nanocrystalline structure. 
The problem of high temperature technological applications of nanocrystalline materials is solved in Hitperm- based alloys $[17,18]$. The combination of FeCo crystalline grains with high magnetization and Curie temperature brought new materials that can be employed even at very high temperature $\left(900{ }^{\circ} \mathrm{C}\right)[19,20,21]$.

In the present work, we introduce novel nanocrystalline microwires with enhanced Curie temperature based on $\mathrm{FeCoMoB}$ alloy composition. They combine the advantages of FeNiMoB nanocrystalline microwires with high magnetization and Curie temperature, together with high structural stability of FeCo-based nanocrystalline materials. In addition, they exhibit magnetic bistability as a consequence of the positive magnetostriction of FeCo crystalline grains. Moreover, their excellent soft magnetic properties are kept after in a wide range of temperatures.

\section{Experimental}

The study has been performed on glass-coated amorphous microwires with nominal composition of $\mathrm{Fe}_{40} \mathrm{Co}_{38} \mathrm{Mo}_{4} \mathrm{~B}_{18}$ prepared by the Taylor-Ulitovsky method. The diameter of the metal core was $16 \mu \mathrm{m}$, and the total diameter was $34 \mu \mathrm{m}$. In order to obtain nanocrystalline structure, the amorphous microwires were annealed for $1 \mathrm{~h}$ at various temperatures ranging from 200 to $600{ }^{\circ} \mathrm{C}$ in argon atmosphere. The structure evolution of microwire was determined through the temperature dependence of resistance, performed in the temperature range from 0 to $600^{\circ} \mathrm{C}$ at a heating rate of $10^{\circ} \mathrm{C} / \mathrm{min}$.

Quasistatic hysteresis loops were measured at room temperature by the static induction method described in [22]. Dynamic switching field was measured by induction method using triangular shaped exciting magnetic field at frequency of $50 \mathrm{~Hz}$ [23]. The saturation magnetization was measured with a vibrating-sample magnetometer under an applied field of $1 \mathrm{~T}$ in the temperature range from 25 to $600^{\circ} \mathrm{C}$ at heating and cooling rates of $10^{\circ} \mathrm{C} / \mathrm{min}$. The same sample was subsequently heated up to the given annealing temperature $\left(400,450,500\right.$, and $550{ }^{\circ} \mathrm{C}$, respectively), then annealed at the given temperature for $1 \mathrm{~h}$, and finally cooled down. Microstructure of the annealed material was analyzed by $\mathrm{x}$-ray diffraction (XRD). 


\section{Results and Discussion}

The measurement of the temperature dependence of resistance is known to be a powerful method to determine the structural changes of materials [24]. Figure 2 shows temperature dependence of resistance. Starting from amorphous state at $27{ }^{\circ} \mathrm{C}$, resistance slightly increases up to $200^{\circ} \mathrm{C}$ as a result of thermal activation of atomic structure. Above $200^{\circ} \mathrm{C}$, structural relaxation takes place up to $350^{\circ} \mathrm{C}$. Such changes are also confirmed by temperature dependence of magnetization and switching field (as will be shown below). Within this range, the stresses and structural defects introduced during the preparation (by rapid quenching and drawing) partly relax and amorphous structure becomes homogenized, which is characterized by a smooth decrease of the resistance of studied material. Above $350^{\circ} \mathrm{C}$, the structural relaxation has already finished and resistance linearly increases up to $420{ }^{\circ} \mathrm{C}$ as it is expected in metallic conductors. At $420^{\circ} \mathrm{C}$, the resistance steeply drops due to the crystallization of $\alpha$-FeCo nanocrystalline grains that are embedded in the residual amorphous matrix, as confirmed by the X-ray measurement (Figure 3).

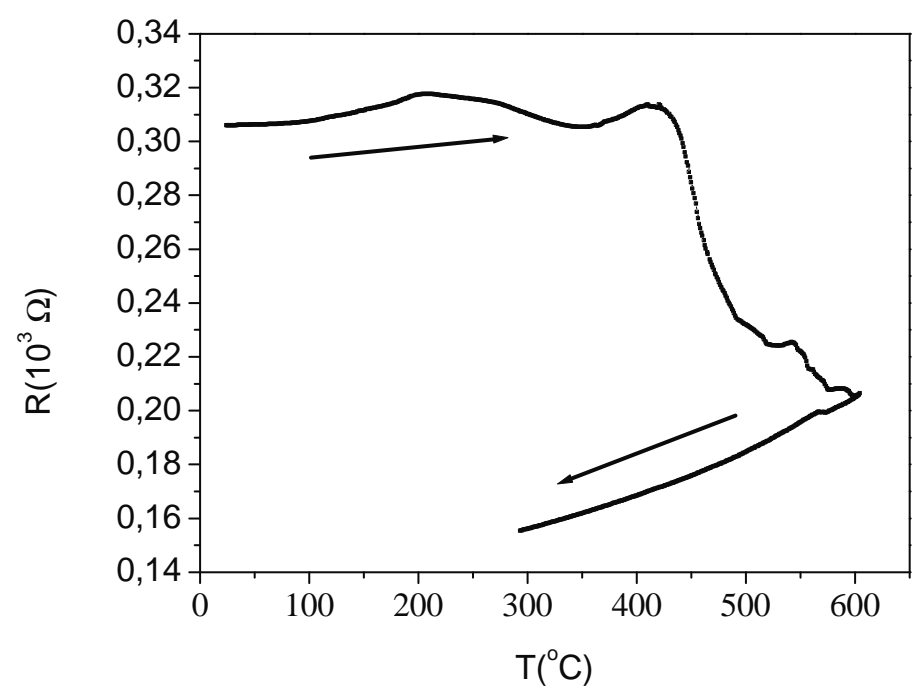

Figure 2.- The temperature dependence of resistance for $\mathrm{Fe}_{40} \mathrm{Co}_{38} \mathrm{Mo}_{4} \mathrm{~B}_{18}$ microwire. Arrows show the temperature running 
The first crystallization step finishes at $540^{\circ} \mathrm{C}$. The crystalline grains in HITPERM based alloys typically consist of bcc $\alpha$-FeCo B2 (ordered) phase [25] which grains size was roughly estimated to be around $19 \mathrm{~nm}$ according to Sherrer's formula. Above this temperature, a kind of secondary crystallization takes place that finishes above $600^{\circ} \mathrm{C}$. However, no new phases were recognized from the X-ray diffractogram (Figure 3), and the crystalline grains size remains nearly constant at $19 \mathrm{~nm}$, hence the second crystallization step should be rather ascribed to the increase of volume fraction of the crystalline phase. As it was shown before [16], strong stresses are generated during annealing in the metallic nucleus by glass coating as a result of different thermal expansion coefficient. Theses stresses inhibit the crystal growth due to suppression of the atomic mobility. Thus, the crystalline grains size remains nearly constant, a requirement of nanocrystalline alloys to show excellent and stable soft magnetic properties [10]. The temperature dependence of resistance for nanocrystallized microwire shows a monotonic decrease with decreasing temperature so, confirming the high structural stability of nanocrystalline materials.

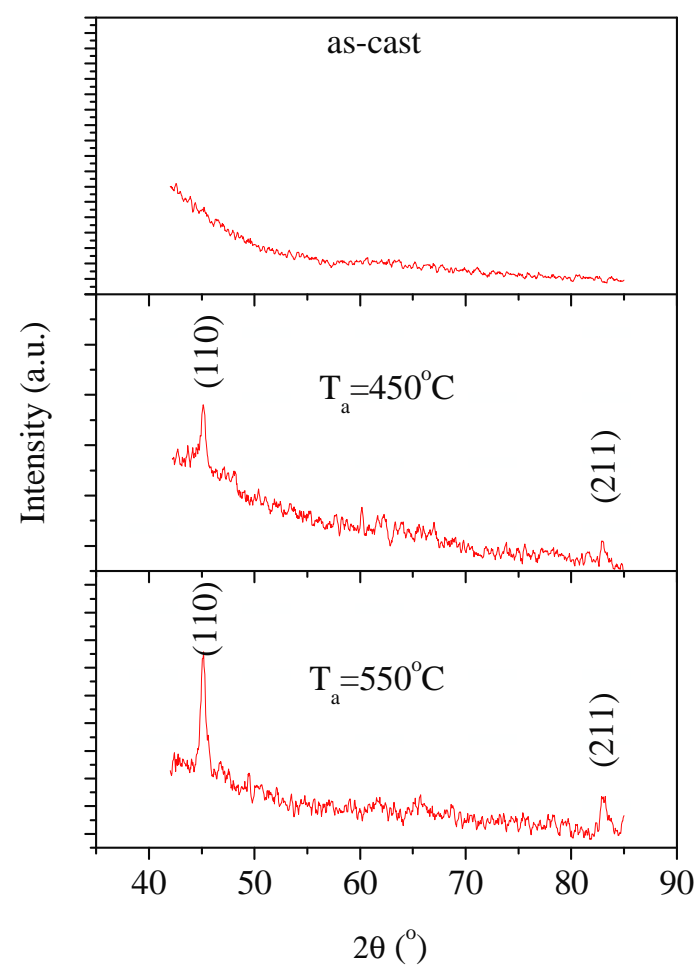

Figure 3.- $X$-ray diffractograms of as-cast and annealed $\mathrm{Fe}_{40} \mathrm{Co}_{38} \mathrm{Mo}_{4} \mathrm{~B}_{18}$ microwire. 
The evolution of the structure was in parallel observed by thermomagnetic measurements (e.g. measurement of temperature dependence of saturation magnetization). Four subsequent runs were performed on the same microwire in order to distinguish different devitrification state of magnetic microwire (Figure 4). In the first run (1. run), the sample was heated from amorphous state up to $400^{\circ} \mathrm{C}$. A typical monotonic decrease of magnetization is observed up to the highest temperature. At $400^{\circ} \mathrm{C}$, the sample was annealed for 1 hour and subsequently cooled down. The stresses and defects introduced during production of microwire were annealed out and magnetization increases in comparison to the as-cast state. This is in agreement to the temperature dependence of resistance that also shows structural relaxation within this range (see fig.2). Moreover, the dependence is smoother after annealing confirming the relaxed structure. The second run (2. run) goes up to $450^{\circ} \mathrm{C}$, at which the microwire was annealed for 1 hour. The temperature $450^{\circ} \mathrm{C}$ is above the crystallization temperature obtained from resistivity measurement (Figure 2). Hence, annealing at this temperature leads to the appearance of FeCo crystalline grains with high magnetization and Curie temperature. The total magnetic moment is increased during annealing. 


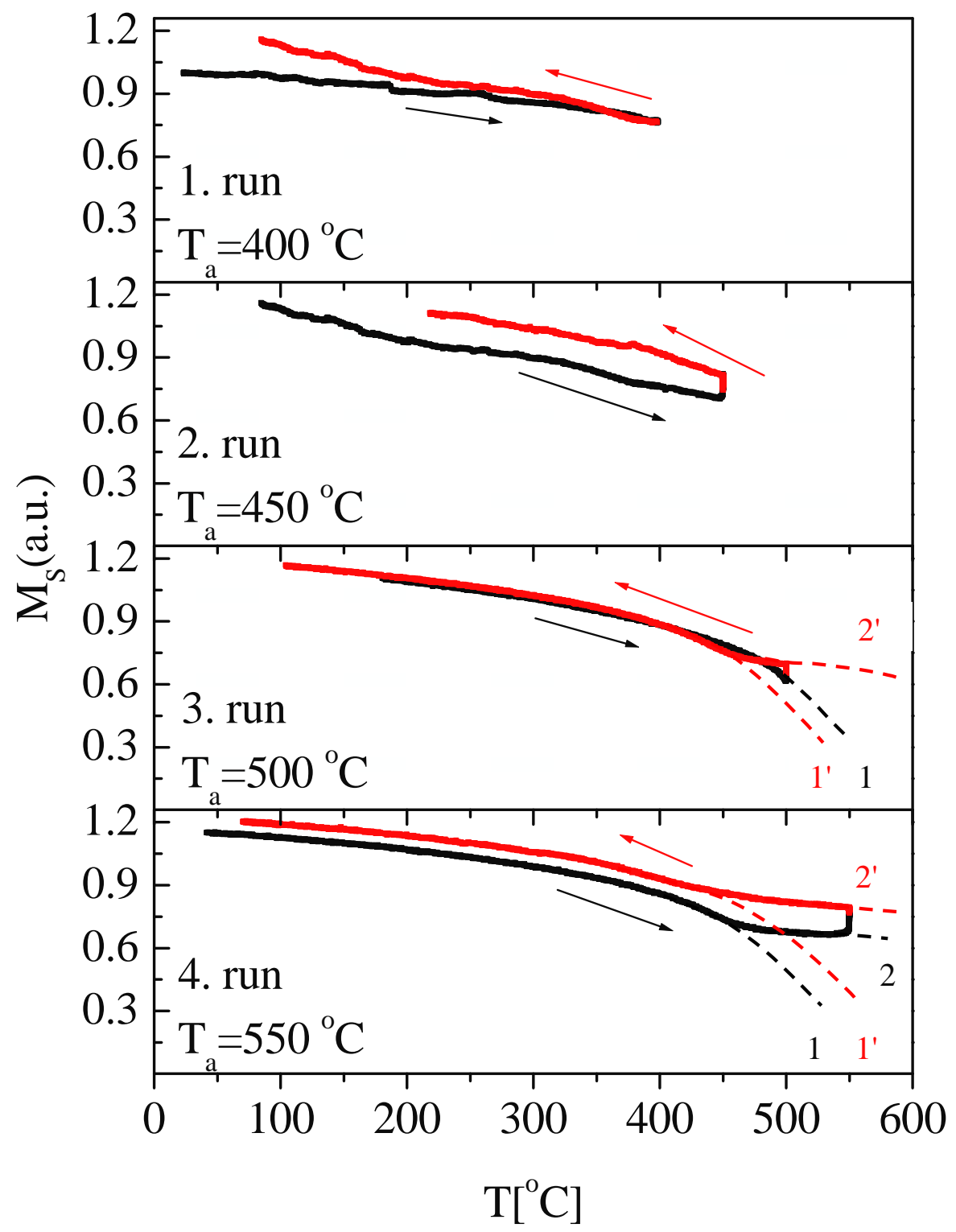

Figure 4. Thermomagnetic analysis of the annealed $\mathrm{Fe}_{40} \mathrm{Co}_{38} \mathrm{Mo}_{4} \mathrm{~B}_{18}$ microwire. Dash lines show assumed/supposed drop of amorphous phase(1) and crystalline phase (2) before (black color) and after annealing (red color or number with dash).

The third run (3. run) goes up to $500^{\circ} \mathrm{C}$, together with annealing at this temperature, that brings further increase of the crystalline volume as demonstrated by an increase of the magnetization. When cooling down to room temperature (red line), the presence of two-phase is demonstrated by the observed change of slope. The Curie 
temperature of amorphous phase (which is above $500{ }^{\circ} \mathrm{C}$ ). The temperature dependence of magnetization for two-component system is given as [20]:

$$
M_{S}(T)=v_{a m} M_{a m}(T)+v_{c r} M_{c r}(T)
$$

where $v_{i}$ is the volume fractions and $M_{i}(T)$ is the saturation magnetization of each magnetic phase [i=amorphous (crystalline)]. Thus, a characteristic kink (at $450^{\circ} \mathrm{C}$ ) below the Curie temperature of amorphous phase is observed. In the fourth run (4. run), the twophase behavior of nanocrystalline microwire is further observed, which is followed by annealing at $550^{\circ} \mathrm{C}$ for 1 hour. Further annealing brings another increase of crystalline fracture in nanocrystalline microwire. The temperature dependence of magnetization shows a high structural stability of nanocrystalline microwire characterized by its high magnetization up to high temperatures (a goal of the present work).

An additional advantage of the proposed composition is its magnetic bistability. Contrary to the classical nanocrystalline compositions (FINEMET, NANOPERM), the $\alpha$ FeCo nanocrystalline grains exhibit positive magnetostriction. Thus, the overall magnetostriction remains positive, which is a necessary condition for magnetic microwires to obtain monodomain structure and hence, magnetic bistability. Figure 5 shows the bistable hysteresis loops of $\mathrm{FeCoMoB}$ microwire in the as-cast state and after annealing at 425 and $550{ }^{\circ} \mathrm{C}$. Note that magnetic bistability is confirmed by the lack of experimental points between the two stable magnetic configurations. The loops measured in the as-cast state and annealed below $425^{\circ} \mathrm{C}$ (not shown) are perfectly bistable, whereas annealing at $425^{\circ} \mathrm{C}$ leads to a slight reduction of the differential susceptibility within the range -100 to $100 \mathrm{~A} / \mathrm{m}$. This could be assigned to the onset of the crystallization process. However, the crystalline precipitates are small and separated by a long distance and they play a role of the pinning centers for the domains. Anyway, the main magnetization process is a single Barkhaussen jump of a single domain wall at a field $100 \mathrm{~A} / \mathrm{m}$ as it is typical for positive magnetostriction microwire [3]. Annealing at temperatures above $425^{\circ} \mathrm{C}$ leads to a further crystallization, during which the $\alpha$-FeCo nanocrystalline grains grows within amorphous matrix. In this state, size of grains is significant and distance between grains embedded in amorphous matrix is smaller than ferromagnetic exchange length $\sim 46 \mathrm{~nm}$ [26], which (together with the random distribution of their crystallographic axis) results in the averaging out of an effective magnetocrystalline 
anisotropy. Thus the microwires remain magnetically soft, and the loops are perfectly bistable due to the positive magnetostriction of crystalline grains as well as amorphous matrix.
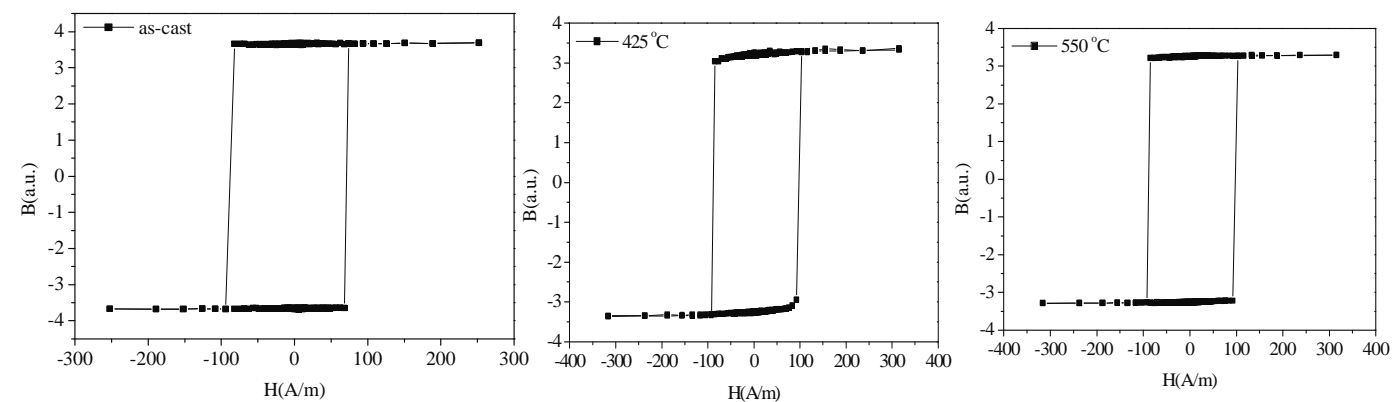

Figure 5.- Hysteresis loops of as-cast $\mathrm{Fe}_{40} \mathrm{Co}_{38} \mathrm{Mo}_{4} B_{18}$ microwire and microwires annealed for 1 hour at temperatures $425^{\circ} \mathrm{C}$ and $550^{\circ} \mathrm{C}$, respectively shows magnetic bistability.

The dynamic switching field and its dependence on the annealing process (Figure 6) reflect the structural changes introduced by annealing. Thermal treatment below $350^{\circ} \mathrm{C}$ releases the stresses introduced during the microwire production (as shown also in resistance measurement in fig. 2), which results in the decrease of magnetoelastic anisotropy and hence decrease of the switching field. Annealing at temperature close to $450{ }^{\circ} \mathrm{C}$ leads to the formation of crystalline grains which being spatially separated play a role of the pinning centers for domain wall motion (see also resistance measurementsfig.2). Hence, strong increase of the dynamic switching field is observed after annealing at $425{ }^{\circ} \mathrm{C}$. Such an increase is not observed in the case of quasistatic loop (Figure 5) because the dynamic switching field measured by the induction method [22] is strongly dependent on the domain wall propagation, whereas quasistatic loops measure only static magnetization state. In the case of well- separated crystalline pinning centers, the domain wall propagation is hindered and the measured dynamic switching fields are higher than static ones. Such hardening is frequently observed after annealing of nanocrystalline samples just below the optimum annealing temperature [13]. 


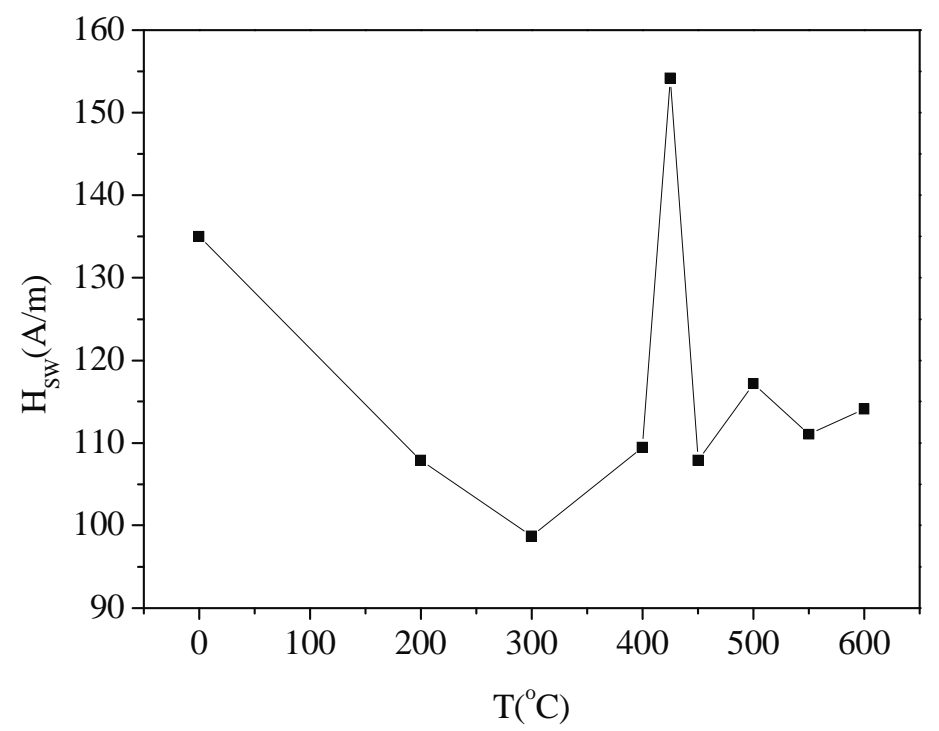

Figure 6.- Dependence of the switching field, $H_{S W}$, on the annealing temperature, $T_{a}$, measured at room temperature at frequency $50 \mathrm{~Hz}$.

An important fact is that the switching field remains nearly constant after annealing above $425^{\circ} \mathrm{C}$ contrary to nanocrystalline microwires with different alloy composition (where annealing at higher temperature results in steep increase of the switching field) $[13,14,16]$. The coercivity of soft nanocrystalline materials is mainly driven by a small magnetocrystalline anisotropy, which is a result of the randomly oriented crystalline grains. Their diameter $(\sim 19 \mathrm{~nm}$ as confirmed by X-ray) is much smaller than the exchange length, hence they are exchange-coupled through the amorphous matrix. As a result of such interaction, the effective magnetocrystalline anisotropy is almost zero. The crystalline grains diameter does not change within a wide range of annealing temperature because of the stress resulting from the glass coating on the metallic nucleus. So, the optimum anealing temperature interval to obtain soft magnetic, bistable microwire is enhanced from 450 to almost $600^{\circ} \mathrm{C}$, in contrary to the classical nanocrystalline material, where optimum annealing temperature ranges typically within a very narrow interval at more elevated temperature (from 530 to $560^{\circ} \mathrm{C}$ ).

Moreover, the crystallization temperature decreases in comparison with the HITPERM alloys by $100^{\circ} \mathrm{C}$. This is seemingly a consequence of using Mo in order to 
inhibit grain growth. As it was shown in [27], Mo decreases the crystallization temperature of nanocrystalline phase in opposition to $\mathrm{Zr}$ or $\mathrm{Nb}$ [18-20]. However, good soft magnetic properties remains and the given composition belongs to the group of softest magnetic nanocrystalline microwire. This is another important fact for production specially in the case of glass-coated microwire, where high temperature annealing results in a strong applied stress due to different thermal expansion coefficient of metallic nucleus and glass coating $[13,14,16]$.

\section{Conclusions}

We present a novel nanocrystalline glass-coated $\mathrm{Fe}_{40} \mathrm{Co}_{38} \mathrm{Mo}_{4} \mathrm{~B}_{18}$ microwire with enhanced Curie temperature. It consists of bcc $\alpha-\mathrm{FeCo}$ (ordered B2 phase) crystalline grains embedded in residual amorphous matrix. The positive magnetostriction of crystalline and amorphous phases results in magnetic bistability of magnetic microwires, which is necessary condition for functional materials used in modern spintronic devices. The exchange interaction of randomly oriented crystalline grains leads to very good softness of presented microwires that makes them very attractive as soft magnetic functional materials. The stresses introduced by the glass-coating during the thermal treatment keep the size of the crystalline grains constant within the studied annealing temperature range. This effect enhances the optimum thermal treatment temperature range from 450 to $600{ }^{\circ} \mathrm{C}$, within which the magnetic softness is high. Use of Mo, instead of $\mathrm{Nb}, \mathrm{Zr}$, in order to inhibit the grain growth decreases the crystallization temperature of nanocrystalline phase, thus reducing the stresses of the glass-coating during the heat treatment.

All the above mentioned features make the nanocrystalline glass-coated $\mathrm{Fe}_{40} \mathrm{Co}_{38} \mathrm{Mo}_{4} \mathrm{~B}_{18}$ microwire ideal functional material for sensoric and spintronic devices.

\section{Acknowledgements}


This work was supported by the project NanoCEXmat, Slovak VEGA grant No.1/3076/09, 2/7193/07 and APVV-0454-07 and project VVGS PF 13/2009/F. This has been also partly supported by the Spanish MICINN under project MAT2007- 65420.

\section{References}

[1] M. Vázquez, Handbook of Magnetism and Advanced Magnetic Materials: Advanced Magnetic Microwires (Ed. H. Kronmüller, S. Parkin), John Wiley \& Sons, Chichester, UK 2007, pp. 2193-2226.

[2] K. Pirota, M. Hernández-Vélez, D. Navas, A. Zhukov, M. Vázquez, Adv. Funct. Mater. 2004, 14, 266268.

[3] R. Varga, K. L. Garcia, M. Vázquez, P. Vojtaník, Phys. Rev. Lett. 2005, 94, 017201.

[4] A. Zhukov, J. Gonzalez, M. Vazquez, V. Larin, A. Torcunov, Encyclopedia of Nanoscience and Nanotechnology: Chapter 62: Nanocrystalline and amorphous magnetic microwires (Ed: H. S. Nalwa), American Scientific Publishers, 2004, 23.

[5] H. Chiriac, T. A. Ovari, Prog. Mater. Sci. 1996, 40, 333.

[6] S. S. P. Parkin, M. Hayashi, L. Thomas, Science 2008, 320, 190.

[7] D. A. Allwood, G. Xiong, C. C. Faulkner, D. Atkinson, D. Petit, R. P. Cowburn, Science 2005, 309, 1688.

[8] M. Vazquez, Physica B 2001, 299, pp. 302-313.

[9] Y. Yoshizawa, S. Oguma, K. Yamauchi: J. Appl. Phys. 1988, 64, 6044.

[10] G. Herzer, IEEE Transaction on Magnetism 1990, 26, 1397.

[11] H. Chiriac, T. A. Ovari, G. Pop, F. Barariu, J. Appl. Phys. 1997, 81, 5817.

[12] C. Dudek, A. L. Adenot-Engelvin, F. Bertin, O. Acher, J. Non-Cryst. Solids 2007, 353, 925.

[13] J. Arcas, C. Gómez-Polo, A. Zhukov, M. Vázquez, Nanostruct. Mater. 1996, 7, 823.

[14] J. Gonzalez, A. Zhukov, V. Zhukova, A. F. Cobeno, J. M. Blanco, A. R. De Arellano-Lopez, S. Lopez-Pombero, J. Martinez-Fernandez, V. Larin, A. Torcunov, IEEE Trans. Magn. 2000, 36, 3015.

[15] R. Varga, C. Luna, A. Zhukov, M, Vazquez, P. Vojtanik, Czech. J. Phys. 2004, 54, 177.

[16] E. Komova, M. Varga, R. Varga, P. Vojtanik, J. Bednarcik, J. Kovac, M. Provencio, M. Vazquez, Appl. Phys. Letters 2008, 93, 062502.

[17] M. E. McHenry, M. A. Willard, D. E. Laughlin, Prog. Mater. Sci. 1999, 44, 291-433.

[18] H. F. Li, D. E. Laughlin, R. V. Ramanujan, Philosophical Magazine 2006, 86, 1355-1372.

[19] Zs. Gercsi, F. Mazaleyrat, L. K. Varga, J. Magn. Magn. Mater. 2006, 302, 454-458.

[20] I. Skorvanek, P. Svec, J. Marcin, J. Kovac, T. Krenicky, M. Deanko, Phys. Stat. Sol. (a) 2003, 196, 217-220.

[21] Ojaswini Mohanta, M. Ghosh, A. Mitra and A. K. Panda, J. Appl. Phys. D. 2009, 42, 065007.

[22] J. Ziman, B. Zagyi, J. Magn. Magn. Mater. 1997, 169, pp. 98-104.

[23] R. Varga, K. L. Garcia, A. Zhukov, M. Vazquez, P. Vojtanik, Appl. Phys. Letters 2003, 83, 2620. 
[24] P. Vojtanik, R. Matejko, R. Varga, V. Ocelik, Mat. Sci. Forum 2001, 373, 237.

[25] M. A. Willard, D. E. Laughlin, M. E. McHenry, J. Appl. Phys. 1998, 84, 6773.

[26] H. Iwanabe, B. Lu, M. E. McHenry, D. E. Laughlin, J. Appl. Phys. 1999, 85, 4424-4426.

[27] C. F. Conde, A. Conde, Rev. Adv. Mater. Sci. 2008, 18, 565-571. 


\section{Axial domain}

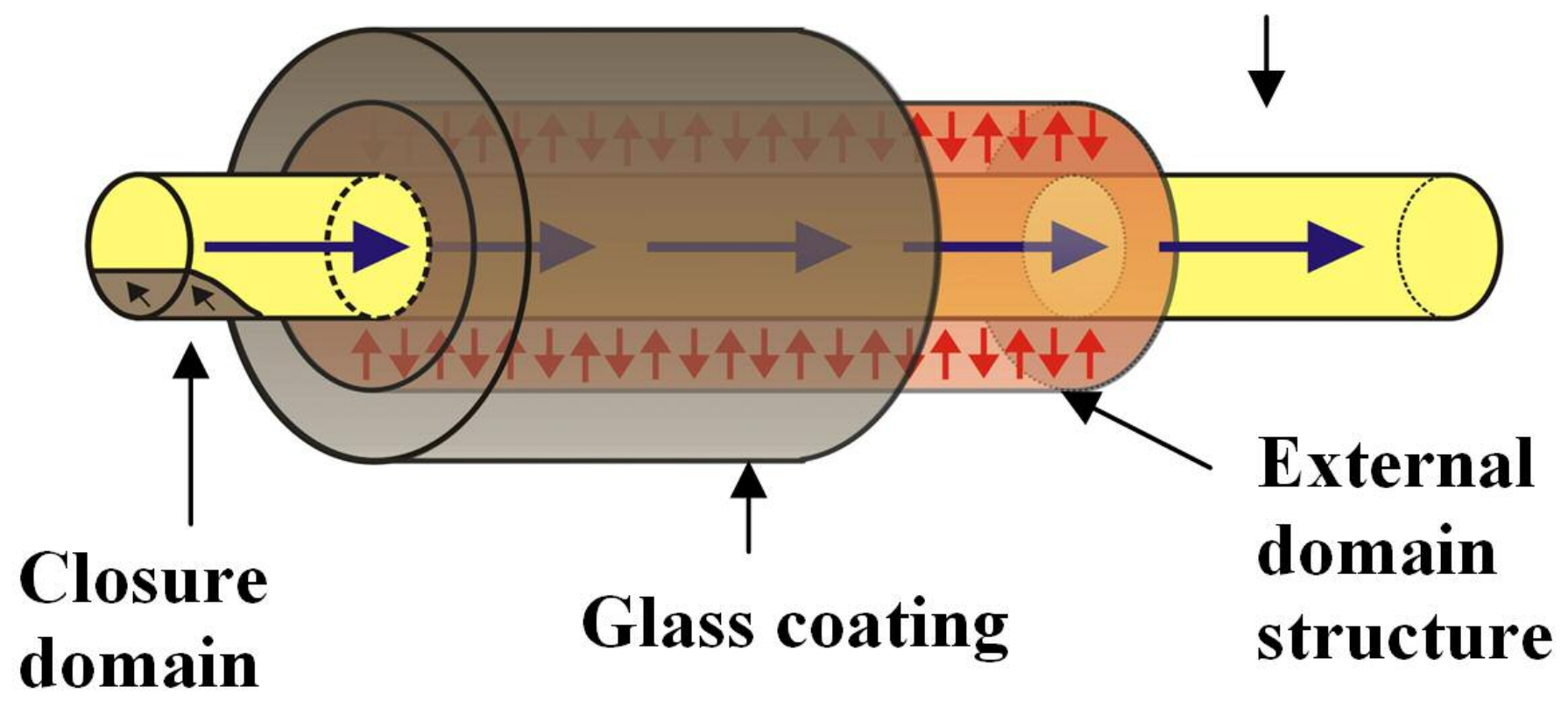

Figure 1 (Figure1.TIF) 


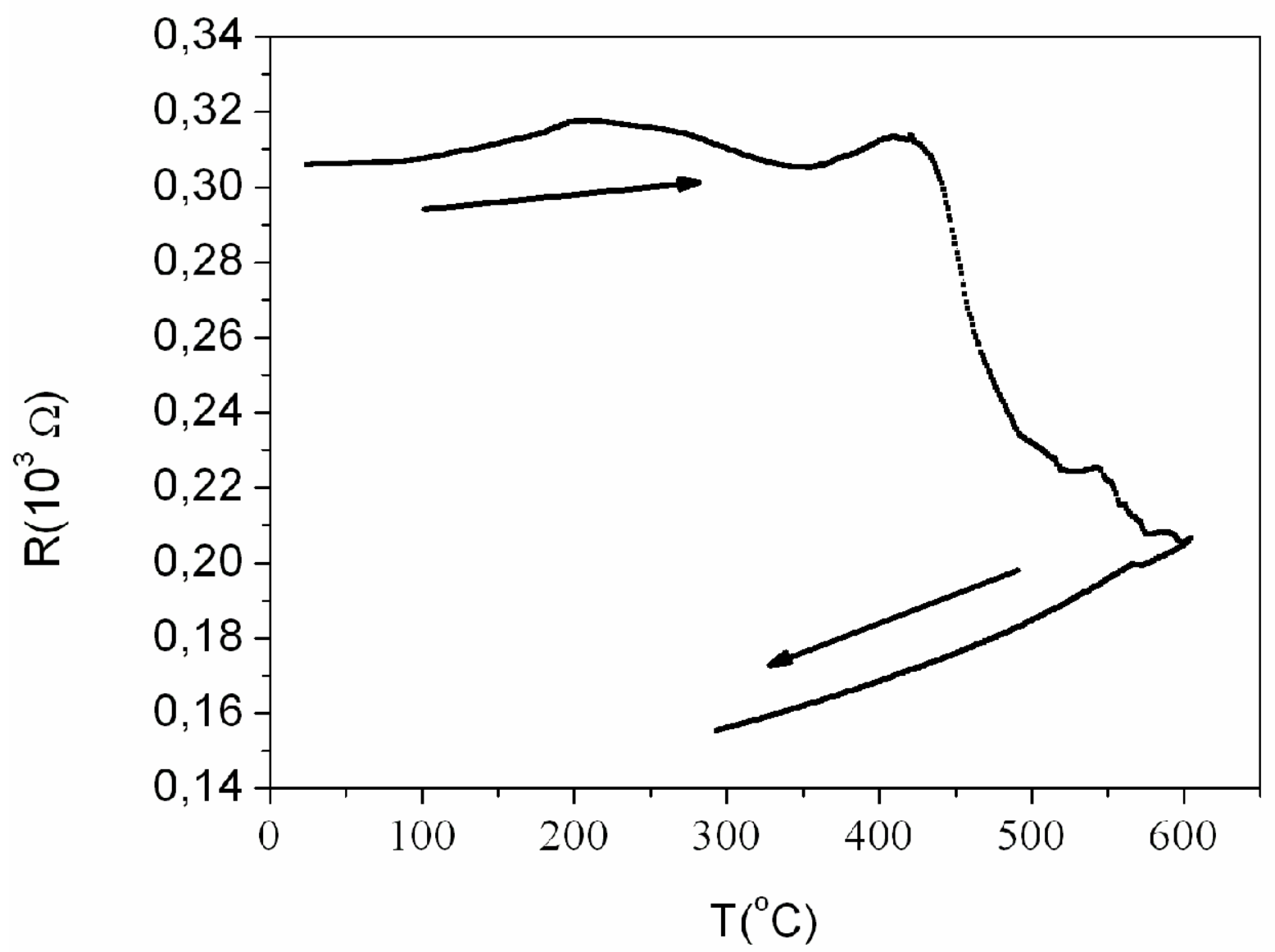

Figure 2 (Figure2.TIF) 


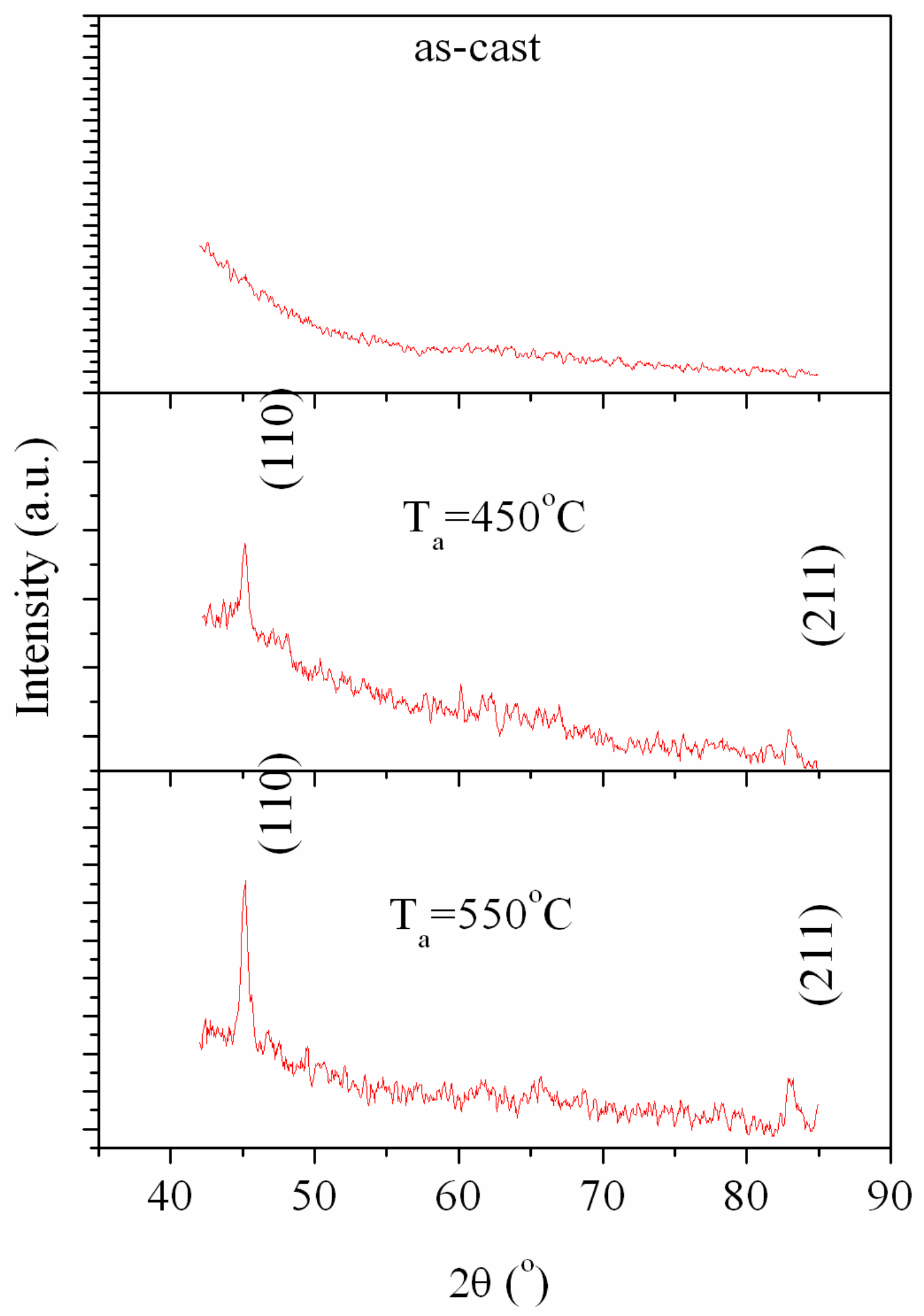

Figure 3 (Figure3.TIF) 


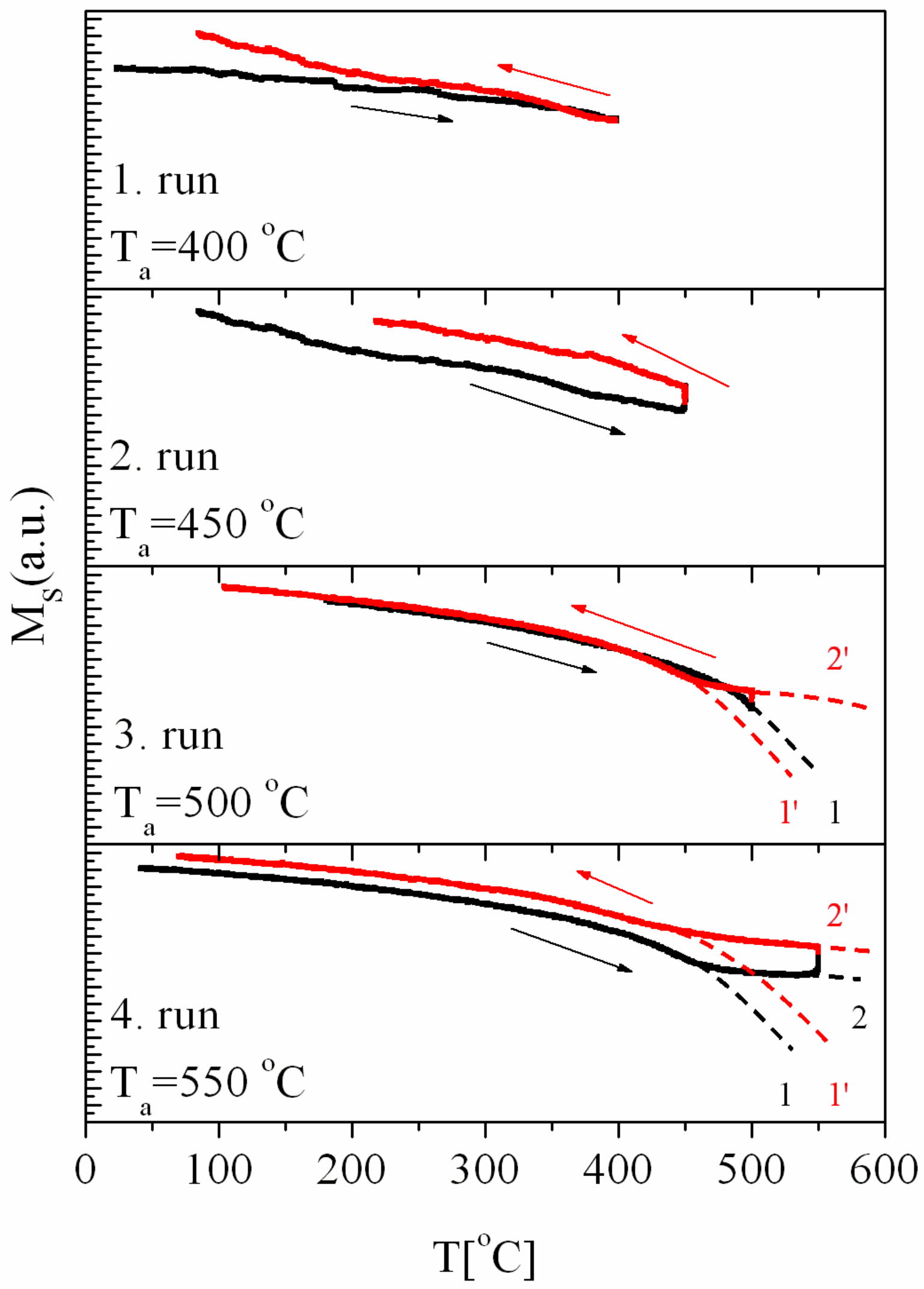

Figure 4 (Figure4.TIF) 


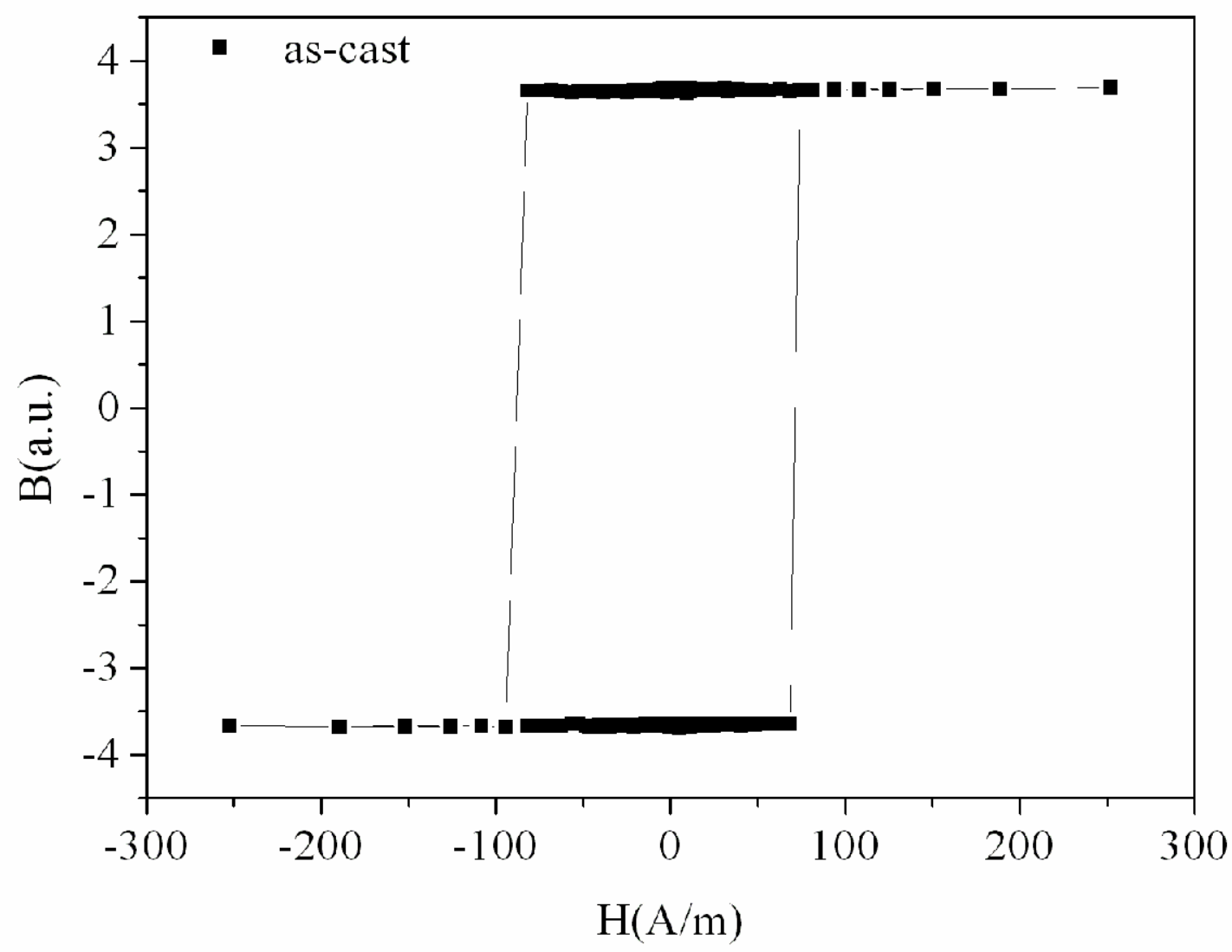

Figure 5 (Figure5a.TIF) 


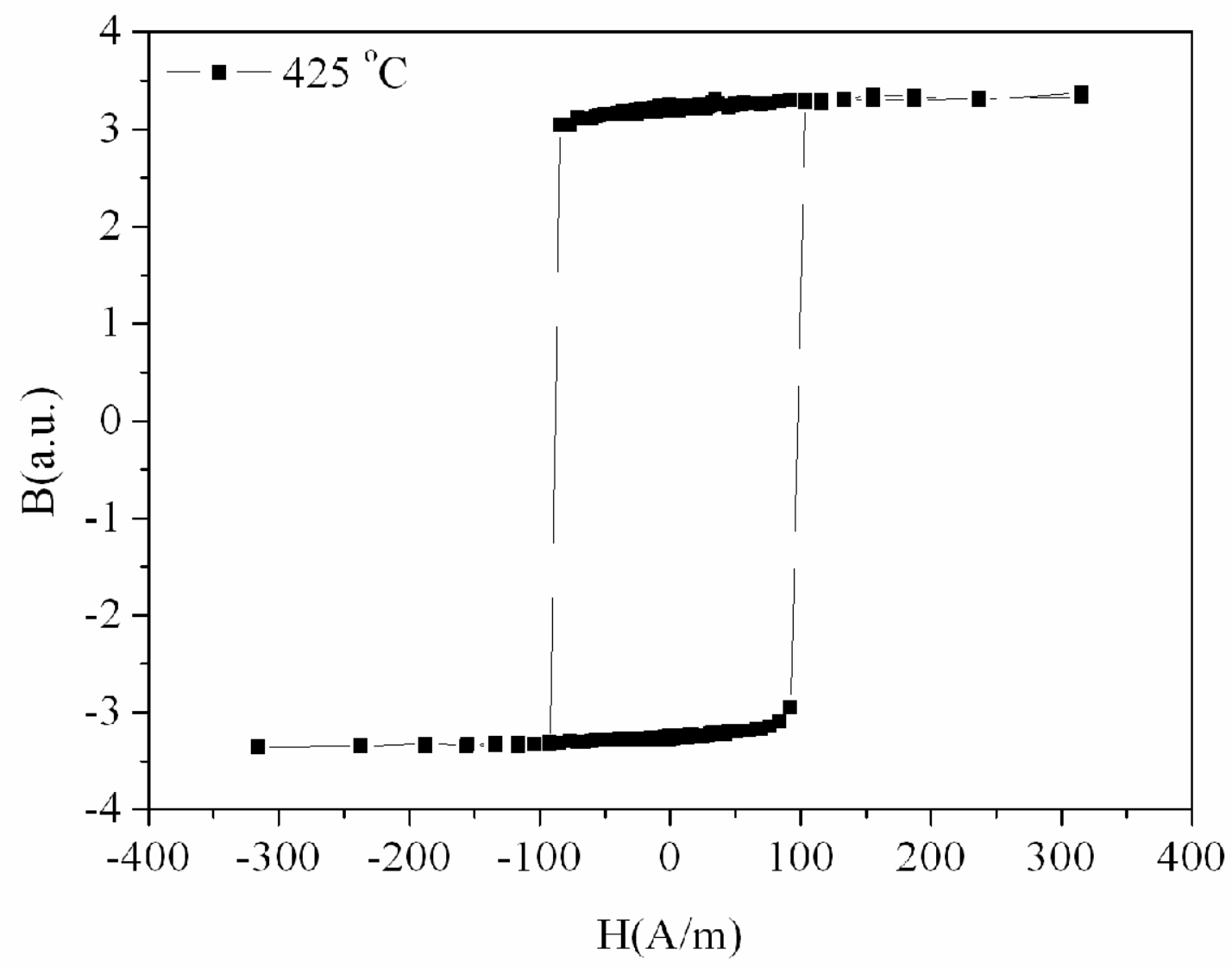

Figure 6 (Figure5b.TIF) 


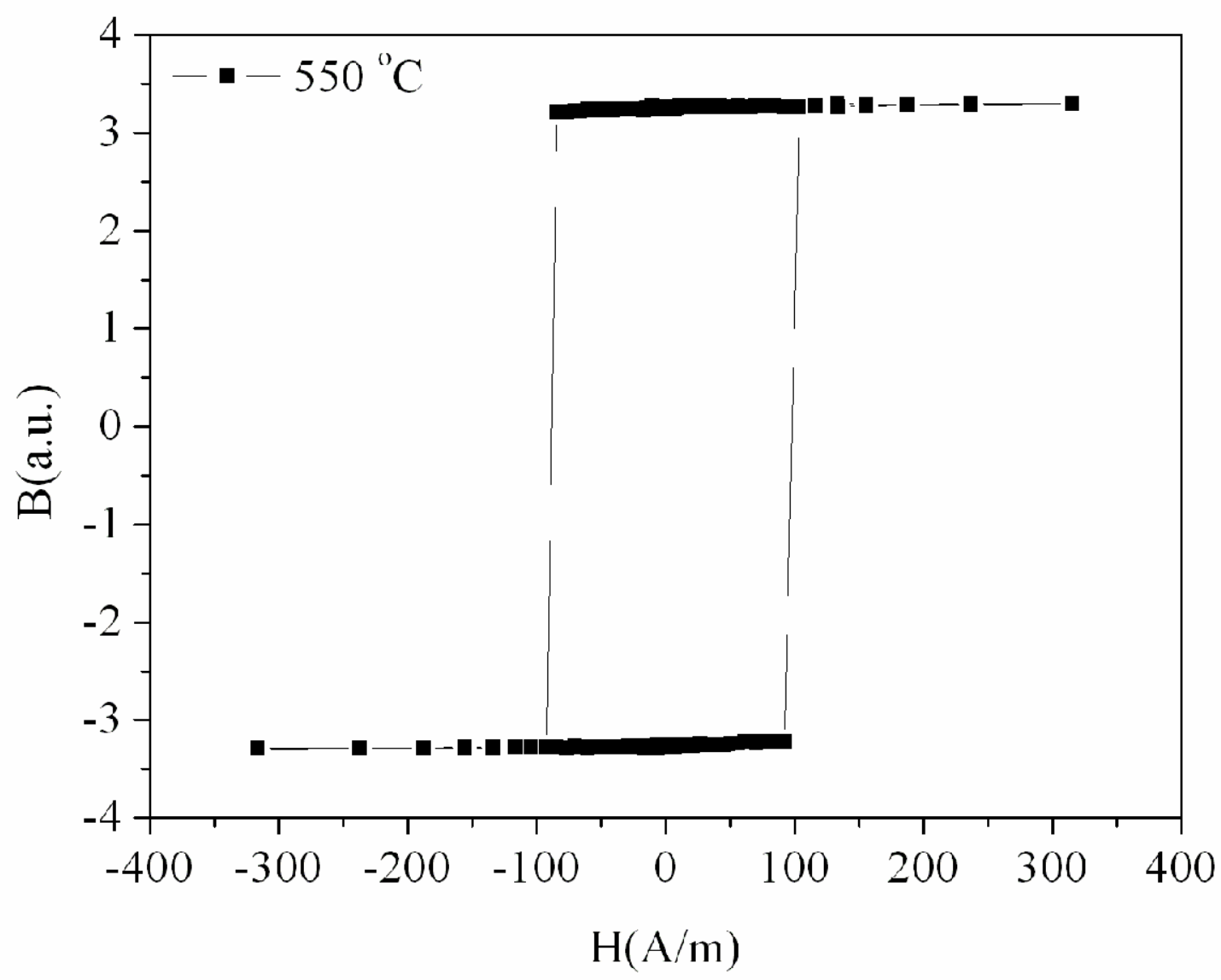

Figure 7 (Figure5c.TIF) 


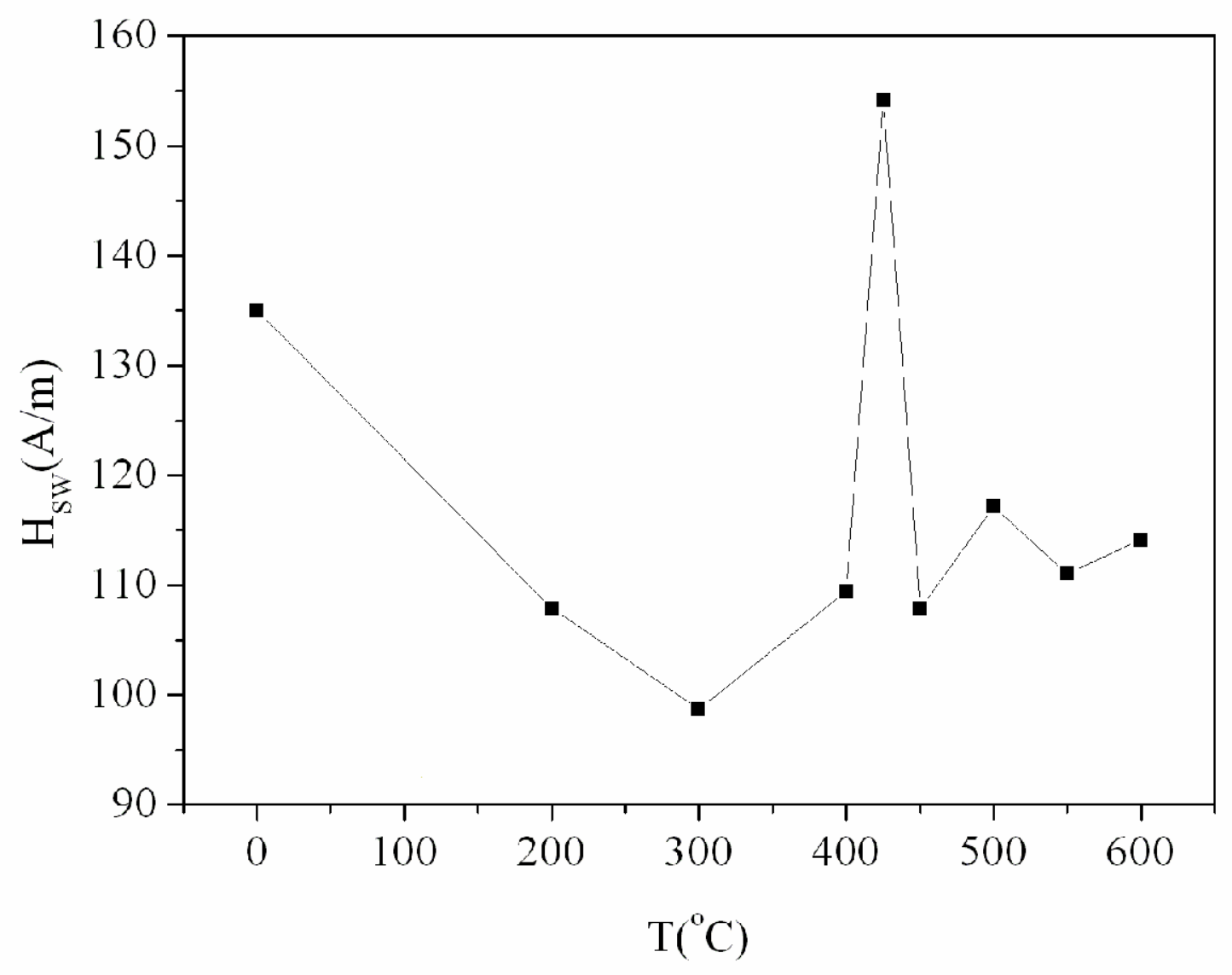

Figure 8 (Figure6.TIF) 